of the fracture. Again, the Judet arthroplasty, either with a metallic or a plastic prosthesis, is no longer one that commends itself to many surgeons.

The style of writing is uneven, passages in narrative form being occasionally interrupted by verbless sentences. The author's instructions for passing examinations are unlikely to be viewed with favour by those responsible for medical education in this country, while his time-table for a rehabilitation centre, allowing 'free time' from I 900 hours to I 900 hours, is likely to meet with a rather mixed reception from those being rehabilitated.

The idea of the book is a good one, much of the information containec' in it is useful, many references are given (though Holdsworth's work on paraplegia is not mentioned) and the standard of production is excellent. A considerable reappraisal will, however, be needed if it is to fulfil its author's expressed aims.

\section{THE PRINCIPLES AND PRACTICE OF DIATHERMY}

By B. O. ScotT, M.R.C.S., L.R.C.P., D.Phys.Med. Pp. vii +193 , with 146 illustrations. London: William Heinemann Ltd. 1957. 25s.

This book is intended for the physical medicine specialist and physiotherapist and is therefore a technical work. However, the style in which it is written is most readable and the more advanced theoretical considerations are separated from the rest of the text. There are numerous diagrams and illustrations and a useful bibliography follows each chapter.

The author has himself carried out original experimental work and writes with the authority of considerable experience of his subject.

\section{EVERYDAY PAEDIATRICS}

By B. Gans, M.D., M.R.C.P., and L. I. Norian, M.B., B.S. Pp. 216 . London: Faber and Faber. I957. I 2s. $6 \mathrm{~d}$.

There is a lot of common sense and useful information in this little book. The part by Dr. Gans, however, gives the impression that he has heard of and applied many of the new attitudes to disease in childhood without really understanding their basic reasons. For example, it is strange to see that the same doctor who calls constipation 'an AngloSaxon neurosis' advises the use of amphetamine sulphate in the treatment of enuresis! Even writing on physical illness Dr. Gans makes some rash statements: 'The practitioner is unlikely to miss a case of intussusception'; the last child your reviewer saw with an intussusception had been a puzzle to an excellent doctor for five days.

The brief section on the child and the community, by Dr. Norman, giving details of the child welfare service, is useful.

Your reviewer is sure that both the authors of this book are good at the practical task of helpingô children and their parents, but their own personal ways can appear misleading in point.

\section{THE CLOSED TREATMENT OF COMMON}

By John Charnley, B.Sc., M.B., F.R.C.S. Second edition. Pp. xii +260 , with 199 illustrations. Edinburgh: E. \& S. Livingstone Ltd. 1957. 50s. 을

Seven years ago $\mathrm{Mr}$. Charnley published the firstes edition of this book, written primarily for the $\vec{\circ}$ resident casualty surgeon. Fearing that it had beenmistaken for an elementary students' manual, he $\vec{\omega}$ has now rewritten and revised it 'at postgraduate $\textrm{ }$ level.' It is perhaps a sign of the times that he haso felt the need to introduce much material defending $\exists$. his advocacy of conservative treatment. Thus a $\omega$ provocative new first chapter is devoted to the main $+\dot{\omega}$ features of bone repair and includes many originalo observations and theories relating to this and the role of operative intervention.

The following chapters are only slightly altered from the first edition and comprise the bulk and the best of the monograph. An excellent practical and theoretical account is given of the closed treatment $T$ ( of common fractures with particular emphasis on을 the primary reduction and immobilization.

Some criticisms are possible. The unwary reader may gain the impression that all finger fractures ape $\overrightarrow{0}$ treated in plaster, for the chapter with this heading is concerned entirely with the author's method ôf treating unstable fractures of the proximal pha anges. There is a rather light-hearted dismissal of finger stiffness due to fixation on the grounds that it will always recover in time. Perhaps it would have been better avoided in the first place by a shorter $\mathbb{D}$ period of immobilization.

It is regrettable that skin traction is so firmly $\overline{\bar{O}}$ condemned. With a little skill and care it is a safe 3 and effective technique.

The index is poor.

The additions to the book have not increased its usefulness to the casualty officer. In fact, by the insertion of much which is, although thought provoking, unproven or debatable, the text has a 3 . generally lowered standard of reliability. Nor is it comprehensive: fractures of the clavicle and 3 scaphoid, for example, are not described.

Nevertheless, this is a very valuable book to study and possess. It provides pleasant, stimulating, $D$ and in places absorbing, reading for all those interested practically and theoretically in what is, $\bar{N}$ after all, the most important way of treating fractures.

A.J.H.

\section{THE FOREQUARTER AMPUTATION}

By H. F. Moseley, M.A., D.M., M.Ch., F.R.C.S., F.A.C.S. Pp. viii +79 , with 25 illustrations and I I plates in colour. Edinburgh: E. \& S. Livingstone Ltd. 1957. $42 \mathrm{~s}$. 